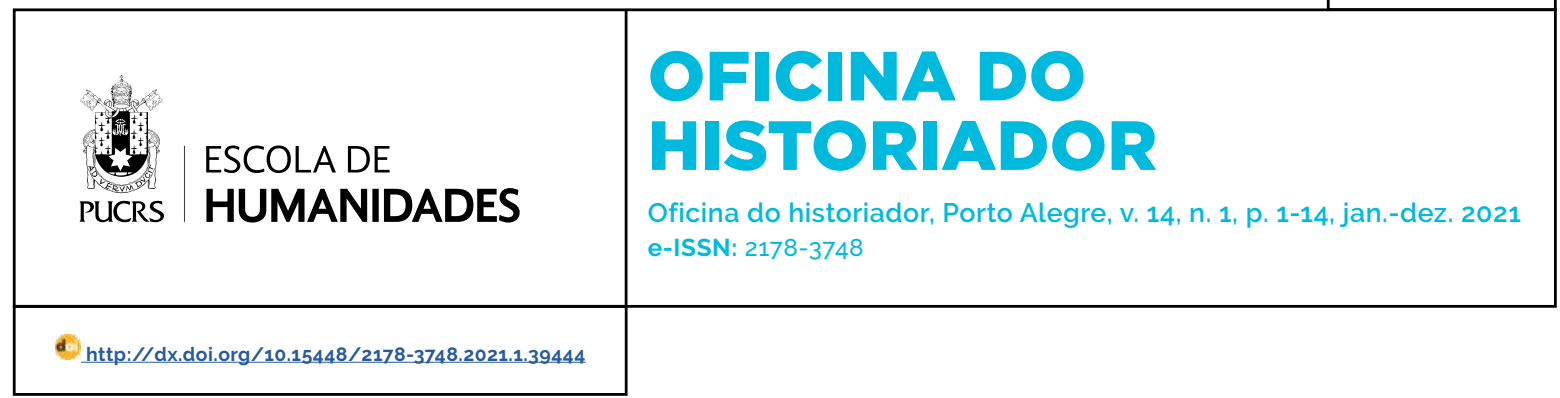

SEÇÃO: ARTIGOS

\title{
A História ilustrada e diligente de Olegário Herculano de Aquino e Castro (1892-1906)
}

The illustrated and diligent History by Olegário Herculano de Aquino e Castro (1892-1906)

Piero Detoni ${ }^{1}$

orcid.org/0000-0002-5106-7868

pierodetoni@gmail.com

Recebido em: 29/10/2020

Aprovado em: $13 / 12 / 2020$.

Publicado em: 13/04/2021.
Resumo: Este artigo reabilita as prescrições historiográficas de um estudioso esquecido pelos círculos de leitores de História da Historiografia brasileira. Falamos de Olegário Herculano de Aquino e Castro, presidente do (IHGB) e do (STF) no alvorecer republicano. Acredita-se que Olegário Herculano teve papel de destaque na defesa das atividades do IHGB em um momento de profundas incertezas, pois era capaz de moderar a herança do passado monárquico e as expectativas republicanas. É possivel dizer que o seu discurso oficial, considerado uma fala autorizada e percebido em suas alocuções presidenciais, seja produto e produtor da experiência historiográfica vivida no IHGB das primeiras décadas republicanas. Apesar de não serem consensuais, as suas prescrições sinalizavam para os interesses de uma parcela significativa dos sócios da agremiação carioca. Em suma, o nosso artigo pretende abordar os contextos epistêmicos (e políticos) que enredavam as reflexões de Olegário Herculano, bem como apresentar ao público em geral esse homem de letras e de Estado ainda pouco conhecido.

Palavras-chave: Olegário Herculano. História. Civilização.

Abstract: This article restores the historiographic prescriptions of a scholar forgotten by the circles of readers of the History of Brazilian Historiography. We tell about Olegário Herculano de Aquino e Castro, president of the (IHGB) and the (STF) at the republican emerge. It is believed that Olegário Herculano had a leading role in defending the activities of the IHGB at a time of profound uncertainty, because he was moderate the heritage of the past monarchy and republican expectations. It is possible to say that his official speech, considered an authorized speech and It's notice in his presidential speeches, whether as a product and producer of the historiographic experience lived in the IHGB of the first republican decades. Although they are not agreed, his prescriptions signalized to the interests of a significant portion of the members of the Carioca association. In short, our article intends to address the epistemic (and political) contexts that entangled Olegário Herculano's reflections, as well as to present to the public in general this man of letters and of State still little known.

Keywords: Olegário Herculano. History. Civilization.

"Ao passado a glória ou o demérito de seus atos; a posteridade o dever de perpetuá-lo".

(Olegário Herculano de Aquino e Castro)

"Escrever história é tarefa difícil e sumamente delicada. O titulo de historiador representa o conjunto de qualidades eminentes do espirito e de coração que nem sempre encontram-se reunidas". (Olegário Herculano de Aquino e Castro 


\section{Introdução}

Na comunidade de leitores de História da Historiografia brasileira Olegário Herculano de Aquino e Castro aparece como mais um ilustre desconhecido. Mais um daqueles estudiosos que não se fixou no cânone historiográfico brasileiro. Absorvido por uma memória disciplinar que não legou aos pósteros as suas ações e as suas performances historiográficas. Talvez alguém que tenha lido algo sobre o Instituto Histórico e Geográfico Brasileiro (IHGB) na Primeira República saiba que Olegário Herculano foi o seu presidente entre 1892 e 1906. Já no campo do Direito o seu nome apresenta-se relativamente lembrado como presidente do Supremo Tribunal Federal (STF) de 1894 a 1906. Capitaneou as duas instituições em um dos momentos mais complicados da história brasileira: aquele que marcou os anos em torno da implementação da República no Brasil. É adiantado uma coisa aos nossos leitores: o seu comando no IHGB foi fundamental para que esse importante grêmio letrado não cerrasse as suas portas na nova ambiência política. Acontece que a subsequente presidência do Barão do Rio Branco silenciou os aguerridos anos em que o Instituto foi dirigido pelo jurista paulista, onde ainda era percebido como uma herança do ancien régime (GUIMARÃES, 2006).

Olegário Herculano de Aquino e Casto nasceu no dia 30 de março de 1828 na capital da Província de São Paulo. Tornou-se acadêmico da Faculdade de Direito da mesma cidade e graduou-se em 23 de outubro de 1848. Um ano depois recebeu o titulo de doutor. Exerceu a magistratura em São Paulo, Goiás e Minas Gerais. Desde 1854, era juiz de Direito. Após esse primeiro momento da sua carreira foi nomeado Desembargador da Relação da Corte, em 1873; presidente da Relação de São Paulo, em 1875; e procurador da Coroa, Soberania e Fazenda Nacional da Corte, em 1883. Após três anos a carreira de Olegário Herculano deu um verdadeiro salto: foi nomeado ministro do STF. Em 1889, recebeu o título de conselheiro de Estado extraordinário. Por fim, foi eleito presidente do STF, cargo que ocupou entre 1894 e 1906, ano do seu falecimento na cidade do Rio de Janeiro. Obviamente que essa narrativa tradicional acionada tem pouco alcance explicativo. Diante da escassez de informações mais detalhadas acerca da biografia intelectual do nosso autor talvez coubessem dois apontamentos de ordem historiográfica: 1) Olegário Herculano foi um sujeito que teve toda a sua formação realizada no período imperial. Quando se tornou presidente do IHGB e do STF ele teve a sensibilidade histórica de não encerrar a história da Monarquia no "deserto do esquecimento", nas famosas palavras de Joaquim Nabuco. O que não significava, certamente, uma apologia da política monárquica; 2) as suas reflexões foram perpassadas pelo ecletismo historiográfico.

Sobre os primeiros momentos em que presidiu - IHGB, que foi no conturbado periodo militar florianista, Olegário Herculano deixou um testemunho acerca de como a agremiação carioca foi atingida em suas atividades acadêmicas em razão daquela atmosfera política atribulada, indo muito além do corte dos subsídios públicos:

\begin{abstract}
É pouco, entretanto, o que tem produzido ultimamente o Instituto; e dir-se-ia que o desânimo vai-se apoderando do alentado espirito de muitos dos nossos consócios, se, para ajuizar da situação em que nos achamos, só tivesse os de atender à escassez de trabalhos apresentados, à falta de leituras instrutivas, e à pouca frequência que de algum modo tem esterilizado as nossas sessões. Mas, cumpre acrescentar, desde já, que circunstâncias anormais têm infelizmente concorrido para tão desfavorável resultado.
\end{abstract}

\begin{abstract}
Foram, como é sabido, muito agitados os últimos tempos, que acabamos de atravessar. Graves acontecimentos de ordem politica, que não nos cabe agora investigar, e a que foi o Instituto inteiramente estranho, influíram para que se paralisasse por muitos meses todo o movimento literário da nossa sociedade, e não pudesse revelar-se a ativa coadjuvação que de costume traziamos para a grande obra a que nos destinamos (CASTRO, 1895, p. 400).
\end{abstract}

No discurso oficial da presidência havia um claro tom de prudência. Encontrava-se, ali, todo um movimento que buscava descolar a agremiação da posição particular de cada sócio. As simpatias dos intelectuais nostálgicos do Império foram habilmente contornadas pela presidência do Instituto, que sabia da necessidade de se adaptar 
aos novos tempos. A partir da direção de Olegário Herculano de Aquino e Castro o IHGB reforçou a sua persona acadêmica, qual seja, a pacifica scientiae occupatio. Era uma ética que desvinculava as atividades dos agremiados da política ordinária, posicionando o Instituto no campo da neutralidade, e que tinha como referente direto a pátria, instância anterior, inclusive, à formação nacional. Por um lado, essa persona orientava os trabalhos acadêmicos dos sócios; por outro, era uma estratégia político-institucional que assegurava o funcionamento do IHGB século $X X$ adentro.

Com as (re)aproximações entre o IHGB e o executivo nacional a partir da presidência de Prudente de Morais, Olegário Herculano, que era presidente do Supremo Tribunal Federal desde 1894, apareceu como uma "ponte" entre a instituição e o poder federal. Isso ficou claro no importante discurso da presidência de 1895:

Ninguém mais que o poder público é interessado na manutenção e desenvolvimento das instituições que têm por fim promover e aperfeiçoar a instrução moral e intelectual, de que depende essencialmente o engrandecimento e o progresso do país; e os nobres e conspícuos funcionários, quando aqui comparecem e abrilhantam nossa reunião, demonstram bem compreender a alta conveniência de favorecer e animar a ação benéfica e salutar influência que exerce a instrução sobre os destinos da sociedade (CASTRO, 1895, p. 408).

Mas Olegário Herculano assinalava, também, que não se devia erigir um muro entre o ontem e o hoje, desejoso de expor que a esperança no futuro e o ânimo do presente relacionam-se com a perpetuação das glórias já colhidas no "longo e honroríssimo passado" (HRUBY, 2007, p. 57). O presidente do Instituto Histórico era uma espécie de mediador entre o passado e o presente político-historiográfico da nação. Não deixando que o estado hodierno apagasse a herança imperial, ao mesmo tempo em que impedia que esse mesmo passado retirasse a legitimidade da jovem República. Olegário Herculano era, pois, um sujeito entre dois mundos.

É preciso destacar que a produção historiográfica brasileira finissecular, ao menos no plano do discurso, distanciava-se dos fazimentos e das práticas de marca romântica movimentadas pelas gerações que fundaram o Império (NICOLAZZI, 2017). Porém, isso não ocorreu de forma abrupta. Olegário Herculano personificava essas atualizações e essas durações, situando-se, também aqui, através das máscaras de um Janus bifronte: romântico-ilustrado e metódico-cientificista. Essas transformações eram desejadas, de uma forma ou de outra, em razão das importantes transformações visiveis na esfera pública local arregimentadas pelos movimentos republicanos (GOMES, 2009), as quais demandavam do plano cultural novos protocolos, diretrizes, exigências e parâmetros, agora científicos, junto à produção de conhecimento, especialmente o historiográfico. De acordo com os pesquisadores Mateus Pereira, Pedro Afonso dos Santos e Thiago Nicodemo:

[...] as diferenças se colocam sobretudo em termos discursivos e geracionais: os historiadores formados no contexto de crise da Monarquia e nos primeiros anos republicanos procuravam se distanciar das gerações anteriores, mostrando-se atualizados nas discussões científicas típicas da Belle Époque (PEREIRA; SANTOS; NICODEMO, 2018, p. 41).

O que cabe assinalar, aqui, é que Olegário Herculano é um historiador, ou melhor, um "pensador da História", que se forma nos moldes romântico-ilustrados, mas articula as suas prescrições no contexto em que sobressai as formas historiográficas metódico-cientificistas. Por isso, o nosso autor está, em sua particular maneira de refletir sobre a prática do historiador, entre o cientificismo da Belle Époque e a sensibilidade romântico-ilustrada. De outro modo, pode-se pensar, em termos sociais, que a sua história que civiliza, de matriz iluminista, é atualizada pelo progressismo daquela Belle Époque. É possivel dizer que as prescrições historiográficas de Olegário Herculano estivessem em um "momento de passagem" entre regimes historiográficos, desde que essa "passagem" ganhe sentido, expressão e que responda a problemas que são pertinentes somente a ela, denotando, então, características historiográficas singulares.

Na transição do século XIX para o XX, momento de consolidação da Belle époque à brasileira, per- 
cebe-se que as reflexões de Olegário Herculano agiam a partir de uma forma especifica de ordenar a temporalidade amparada por uma ideia de progresso em conexão com um conceito de civilização que se performava entre antigos e modernos. Por intermédio dela parecia crivel elaborar um registro histórico de caráter evolutivo. A moralização do conceito de civilização, de matriz eurocêntrica, mais precisamente de origem francesa, por parte de Olegário Herculano, decorrente da presença dos antigos em seu pensamento, aproximava a sua concepção de história de expressões que denotavam "movimento", "transformação", "progresso", "decadência" e "degeneração". Esse registo era o próprio processo de atualização do conceito de história na modernidade (NETO, 2015). Em Herculano havia uma coadunação entre preceitos antigos e modernos de história, em termos de processo e de conhecimento, pressionada pelas demandas "progressistas" colocadas a partir da Belle Époque brasileira e, por conseguinte, por todo um novo referencial conceitual, notadamente de cariz francês, que mediava as relações e as influências entre Brasil e Europa a partir do processo de apropriação.

O texto a seguir está preocupado com questões de Epistemologia da História, fartamente pronunciadas por Olegário Herculano na fala oficial do presidente nas sessões de aniversário do IHGB. A partir desse material é traçada uma cartografia das suas principais preocupações historiográficas. Os seus pronunciamentos são fatos e indicadores acerca da experiência historiográfica inscrita nas primeiras décadas republicanas. Percebe-se que o nosso autor acomodava distintas concepções de história em suas reflexões. Essa característica, mais do que um obstáculo para essa investigação, apresentava-se como uma forma possivel de evidenciação dos contextos historiográficos disponiveis na ambiência aludida.

\section{Um moderno "conceito antigo" de história?}

Olegário Herculano de Aquino e Castro articulava modos antigos e modernos de história em suas prescrições. Mais do que uma incongruência, essa disposição epistêmica se mostrava como um sinal consistente das formas como era experienciada a história, como processo e como disciplina, na Primeira República. Destacavam-se os elementos antigos que perduravam em sua concepção de história: ela era "mestra da vida" (CASTRO, 1892, p. 427), "fonte de luz inextinguivel na senda tortuosa da existência" (CASTRO, 1892, p. 427), "compêndio de inestimáveis ensinamentos" (CASTRO, 1892, p. 427), "testemunho irrecusável dos tempos" (CASTRO, 1892, p. 427), descrição fiel do "caráter pessoal e político dos homens que mais se tem distinguido descrevendo com discernimento a influência que vieram a exercer" (CASTRO, 1892, p. 427). Dessa forma, Olegário Herculano "reafirmava as virtudes do modelo da historia magistra vitae, insistindo no seu papel de união entre passado e presente, mas também entre presente e futuro: a História nos une aos séculos passados e transmite o que nós somos aos séculos futuros" (HARTOG, 2017, p. 12). Contudo, o seu conceito de história trazia aspectos que eram modernos. Esse entendimento era devedor, principalmente, das leituras das obras do historiador português Alexandre Herculano. Assim, a história tinha como destino o enriquecimento do futuro com a experiência do passado. A História, como também havia sido para os antigos, possuía como escopo a verdade, mas entre os modernos esse horizonte epistêmico tinha como encargo o acompanhamento da "marcha progressiva da humanidade" com rigorosa exatidão, imparcialidade conscienciosa e indefectivel justiça, dimensões atualizadas dos antigos para o regime científico da passagem para o século XX. "Já se encontram aí, de fato, os componentes do conceito moderno de história: o tempo como ator e agente, assim como a distância histórica, entre o campo de experiência (a lembrança) e o horizonte de expectativa (a esperança) (HARTOG, 2017, p. 13).

Mas o que acontecia era a duração das funções edificantes antigas. De qualquer modo, a forma como Olegário Herculano, e parte significativa dos seus contemporâneos, percebia o conceito de história nos faz pensar que os modernos atualizavam os antigos, o que implicava na so- 
brevivência desses em uma episteme diferente. Não se deixava de aprender com a história, como ela não deixava de ser edificante. O novo aprendizado da história era concebido através da noção de formação. Aprender com a história era, dessa forma, uma maneira positiva de avaliar a conjuntura com vistas ao aumento da previsibilidade do futuro (ARAUJO, 2011).

Mais uma vez pode-se acompanhar o consórcio entre história antiga e moderna percebido nas prescrições de Olegário Herculano. Mais do que um equívoco epistemológico as suas escolhas historiográficas são, como dito, fatos e indicadores da historiografia praticada na passagem para o século XX. A sua identidade foi elaborada justamente pelo jogo de aproximação e de distanciamento entre os polos antigo e moderno. Plutarco era, por exemplo, acionado naquele contexto no que concernia ao entendimento da "sublimidade da história" (CASTRO, 1898, p. 730)_: a "viva testemunha dos tempos" (CASTRO, 1898, p. 730), a "luz da verdade" (CASTRO, 1898, p. 730) e a "escola da experiência" (CASTRO, 1898, p. 730). Compreendido isso, o historiador grego assumia, no entender do conferencista, que diante da razão humana, tardia em progressos, se fazia necessário um guia que direcionasse de modo esclarecido a sua "marcha" incerta e demorada em busca das verdades essenciais. Esse guia era a história. 0 conhecimento da história se performava a partir da exemplaridade, orientando os agentes sociais no tempo. Mas o leitor deve se atentar para o fato "desse Plutarco" estar atualizado para o contexto epistêmico-historiográfico moderno. Ele foi lido por Olegário Herculano com os olhos no presente. De todo modo, esse registo implicava na preservação, e na atualização, de parte importante do seu pecúlio intelectual, como se podia ver logo acima na interpretação do conselheiro.

Após evidenciar a dimensão providencial, muito cara em sua concepção de História, Olegário Herculano novamente promovia uma aliança entre as disposições historiográficas antigas e modernas. Isso poderia ser assimilado a partir desta fala:

Assim é que pela tradição, pela sucessão dos fatos, análise dos acontecimentos, apreciação do caráter dos homens que neles figuram e pelo ponderado estudo dos fenômenos da vida social, vem a ciência da história a exercer direta e incontrastável influência sobre o desenvolvimento, progresso e civilização de um povo (CASTRO, 1898, p. 730).

O conceito moderno de história não suplantava o antigo, mas o posicionava a partir de um jogo dinâmico que envolvia as ideias de inovação e de tradição. Ter essa consciência vigilante oferece uma sobrevida à historia magistra vitae depois do canônico anúncio da sua dissolução (KOSELLECK, 2006).

Continuava-se com a caracterização do conceito de história realizada por Olegário Herculano. A História era, em sua visão, a expositora fiel dos fatos a partir de uma abordagem que sublinhava as suas causas e os seus efeitos. Ela tinha a capacidade de apreciar a "fisionomia moral" dos agentes históricos e da sociedade que faziam parte. Ademais, valendo-se das obras do historiador Alexandre Herculano, o saber histórico se performava como a própria vida da humanidade a partir de todas as etapas e manifestações. Era a Ciência Social que tinha a missão de "enriquecer" o futuro por meio do plano experiencial do passado. No limite, era a moderna história mestra da vida. O conferencista argumentava que a história atual se engradecia com "as gloriosas tradições do passado", aviventando entre os seus coevos aquilo que Sainte-Beuve denominou "espirituosamente" de "suave perfume da antiguidade" (CASTRO, 1891, p. 320).

Ao falar da aplicabilidade da História, Olegário Herculano de Aquino e Castro tornava a movimentar as conexões entre antigos e modernos. Desse modo, na linguagem dos chamados grandes mestres da História não possuía aspecto "decorativo", mas uma função altamente civilizadora: era a luz dos tempos, o repositório fiel dos acontecimentos que mudavam os rumos do mundo, a testemunha irrecusável da verdade, a voz dos bons conselhos e da prudência, a regra de conduta e a escola dos costumes. Como podia ser verificado nessa reflexão privilegiavam-se aspectos do conceito antigo de história atualizados para o mundo moderno. O conceito moderno 
de história agenciava a temporalidade. Se me permitem a licença historiográfica: me parece que em Herculano encontrava-se um moderno "conceito antigo" de história. De todo modo, sem o conhecimento do passado os agentes estariam restringidos no tempo e no lugar em que viviam, reféns de um saber individual e pouco reflexivo; alienados, inertes e em uma espécie de "eterna infância". Em suma, estranhos ao que se passava no resto da sociedade, bem como em estado de ignorância diante do passado, do presente e do futuro (CASTRO, 1901, p. 321). Por isso a necessidade da crença em história. "Trata-se ai do crer em, como cremos em Deus, no mais alto grau da crença" (HARTOG, 2017, p. 10, grifo do autor).

\section{A História que civiliza}

O presidente do IHGB argumentava que os estudos históricos, em todos os tempos e em todas as partes, chamavam a atenção dos ditos sujeitos ilustres, "verdadeiros fanais da opinião" (CASTRO, 1901, p. 321), "preceptores da sociedade" (CASTRO, 1901, p. 321), responsáveis diretos pela educação dos povos os situando na temporalidade moderna, onde se extraía lições do passado por meio do estudo, da observação e da prática de vida, com o desejo manifesto de se atingir um suposto futuro benfazejo. Como se vê a sua História que ilustrava, e civilizava, também era aristocrática.

Assim sendo, não era apenas no âmbito da política, da administração, da indústria, das artes, em tudo aquilo que movimentava a atividade humana, que se situava as preocupações da História. Porém, a sua utilidade pragmática (HEGEL, 1990) promovia o adiantamento do país e a estabilidade das suas instituições liberais. Ou seja: o conteúdo do conceito de história abrangia essa preocupação pública. Mais: o conhecimento histórico instaurava o processo racional-civilizador junto à sociedade. ${ }^{2}$ Em suas próprias palavras:

É ainda no apurado estudo das letras e no desenvolvimento da instrução superior, mediante educação moral e intelectual bem dirigida, que consiste o engrandecimento e o progresso que constitui a verdadeira civilização; e certo que sobre bases sólidas e amplas, porque a ciência representa a superioridade da inteligência sobre a matéria, da razão sobre a força, e da verdade sobre os erros acumulados pela ignorância ou pela "paixão (CASTRO, 1896, p. 347).

Mas o que era a civilização, que tanto preocupava os homens de Letras? Quem ensinava o seu significado era, entre outros, o historiador francês François Guizot. Era o aperfeiçoamento social; a evolução histórica; o progresso da humanidade, mediante o melhoramento das condições de existência; o aperfeiçoamento moral pela instrução, pelo trabalho, pela indústria, pela riqueza, pela afetividade do direito, pelas liberdades públicas - elementos basilares para a prosperidade da nação. Nas páginas da História os cidadãos adquiriam o entendimento necessário para engendrar as demandas da civilização. A história era o guia por onde as suas luzes racionalizadoras podiam afluir em direção às nações. Percebe-se na leitura que Olegário Herculano fez de Guizot elementos que formavam um ideal de civilização amparado em tudo aquilo que a sociedade ocidental atualizava das sociedades antigas. Segundo Elias:

Com essa palavra, a sociedade ocidental procura descrever o que lhe constitui o caráter especial e aquilo de que se orgulha: ao nivel de sua tecnologia, a natureza de suas maneiras, o desenvolvimento de sua cultura científica ou visão de mundo, e muito mais (ELIAS, 2001, p. 23).

A percepção do conceito de civilização por parte do Conselheiro Olegário Herculano diferia relativamente da enunciada por Guizot e da estudada por Norbert Elias, dado que ao invés de interditar a herança dos antigos havia o processo de incorporação seletiva da mesma. O conteúdo do seu conceito de civilização era devedor dos valores exemplares do mundo antigo. Civilizar significava, no limite, ensinar modos de ser no mundo. O progresso, na concepção do presidente do IHGB, caminhava no sentido da moral edificante. Desse modo,

\footnotetext{
2 Assim posto, compreende-se que as reflexões de Olegário Herculano de Aquino e Castro estavam, em parte, enredadas peloo cronótopo historicista: o "[...] modelo historicista de identificar regularidade de transformação histórica existia como base de previsões. Identificando regularidades da transformação histórica costumava-se projetar cenários no futuro e então ter uma orientação para a ação" (GUMBRECHT, 2011, p. 33).
} 
O verdadeiro progresso, distintivo da civilização, é o aperfeiçoamento moral que, pela cultura do espírito, nobilita o caráter, exalta o sentimento, incutindo no homem a consciência do dever, da dignidade e da honra. Esse só se expande por meio das ideias, pela ação criadora e benéfica das boas doutrinas, porque só as ideias zombam dos tempos e das distancias, atravessam o espaço e por toda parte manifestam-se, fazem-se ouvir e compreender (CASTRO, 1898, p. 731).

Para Olegário Herculano, a civilização era o espaço possivel onde se podia buscar o estabelecimento das normas, onde era possivel discernir os princípios que produziam o bem da humanidade. Pela História, que ditava as melhores lições para essa mesma humanidade, se podia conhecer o estágio do processo civilizador em cada nação. Ela era um termômetro acerca do grau de moralidade que circunscrevia o plano da civilização. Ademais, por meio das letras, das ciências e das artes, "onde resplandecem essas belas imagens que glorificam a natureza humana", encontrava-se o domínio civilizacional "proclamado pela voz da história, que é voz irrecusável da verdade" (CASTRO, 1898, p. 732). Note-se que a civilização era um fenômeno moderno, porém, o conteúdo do seu conceito indicava atualizações do mundo antigo. "Será sempre digno de louvor e aplauso o apreço dispensado às letras e às ciências, seguros elementos da verdadeira civilização" (CASTRO, 1899, p. 408). Não pode deixar de ser dito que a representação da nação brasileira enquanto herdeira da civilização no novo mundo fazia parte de uma tradição historiográfica que podia ser remetida à fundação do IHGB em 1838. Manoel Luiz Salgado Guimarães salientou que nesse processo de atribuição de identidade se definia o "Outro" da nação, no caso negros e indios (GUIMARÃES, 1888, p. 7). Talvez em Olegário Herculano houvesse uma maior abertura do conceito, mas pela sua própria lógica performática ele continuava marginalizando segmentos sociais, especialmente as chamadas sociedades contemporâneas "primitivas", mesmo que o seu mote fosse o de levar as luzes para todos.

Um passo decisivo, na visão de Olegário Herculano, para a consecução da civilização no Brasil relacionava-se com o estabelecimento da ins- trução pública. Era na consciência nacional que residia todos os benefícios que derivavam da organização e do aperfeiçoamento do ensino "facultado às classes populares". A concepção de instrução para o presidente do IHGB possuía apelo ilustrado: desejava-se levar as luzes por todas as partes como forma dos agentes sociais racionalizarem as suas posições no ambiente social, bem como as suas vidas vistas pela ótica dos fins. Era um processo civilizador que pretendia "polir" a população, resultando na marginalização de setores sociais com identidade e com cultura próprias pela universalização das luzes. Civilizar implicava, pois, a imposição de modos de ser no mundo.

O moralismo de Olegário Herculano, em um jogo entre antigos e modernos, ambicionava, de algum modo, ser esclarecido. A moralidade, engendrada pela História, subsidiava a civilização. Havia uma herança iluminista inegável nas reflexões do presidente do IHGB, transpassada por preocupações que eram dos antigos. Os preceitos da moralidade eram vistos e percebidos pela sua própria voz:

\begin{abstract}
as verdadeiras glórias são as que consistem no conhecimento e na prática das irrefragáveis leis da humanidade; na realização das grandes ideias e generosos cometimentos; são as que com heroismo entrelaçam a sabedoria e a prudência, a liberdade e a ordem, a moral e a virtude; as que assinalam o triunfo incruento da justiça e da equidade nas lutas da vida, sem o turvo contraste que muitas vezes empana o brilho e desmerece a fama desses grandes homens da antiguidade, relembrando as lamentáveis cenas, as violências e os excessos a que foram talvez levados pela impetuosidade das paixões ou pelo prejuizos dos tempos que atravessaram (CASTRO, 1899, p. 409).
\end{abstract}

Dito isso, Olegário Herculano voltava-se mais uma vez para o papel da História na construção de uma "civilização nos trópicos". Todos os povos civilizados deviam conhecer as suas histórias. Necessitavam, para serem percebidos como civilizados, "perscrutar as tradições do passado", delineando as "memórias do tempo", como forma possivel de ajuizar as condições do presente e conjecturar o futuro. Assim sendo, era incontornável que esses povos, que desejam ser civilizados, acompanhassem, pela História, 
a vida social em todas as suas fases evolutivas. A História oferecia aos povos civilizados a chance deles percorrem as características de cada época das suas formações, a sua "indole", além dos principais valores correntes em certas situações históricas. Pragmaticamente, a história acompanhava o curso do devir histórico, apreendendo o que ligava os acontecimentos de modo relacional. Ademais, determinava, através da justiça, o caráter de homens e de mulheres ao longo do tempo, que por meio do pensamento e da ação salientavam-se no "cenário" societário. Enquanto "drama eterno", levava os domínios de Clio a representarem os embates entre o direito e a força, entre as paixões e os interesses, disposições constituintes da própria humanidade que desejava se ver, agora, ilustrada.

A História possuía a capacidade, segundo o conselheiro, de se performar como uma ciência que desvendava aos olhos dos contemporâneos todos os extratos de tempo e todas as configurações espaciais disponíveis, pondo os cidadãos em contato com a exemplaridade do passado. E "pelas reflexões que nos sugere e meditado estudo a que nos leva, em breve nos instrui mais do que o poderiam fazer as sábias lições dos nossos preceptores" (CASTRO, p. 321). Era uma escola de doutrina e de moral. Dela dependia a civilização, condição para aqueles que "amavam o Brasil", em que havia o respeito pelas tradições do seu passado e pelas especiais condições da sua atualidade. A civilização apontava para dois flancos: era uma forma de descrever as sociedades do passado, a partir de uma perspectiva histórica e antropológica; por outro lado, o conceito era um ideal europeu, sendo uma espécie de ideologia moderna que caracterizava o ocidente. O conceito de civilização se performava através dessa ambiguidade, dado que misturava um registro descritivo com outro que era objetivamente moral, organizado, inclusive, por juízos de valor (DUFAL, 2018, p. 2-4). Em Olegário Herculano é acrescido o apelo ao passado.

Em conformidade com os esforços da inteligência Olegário Herculano considerava emergir as ideias edificantes capazes de tornar os cidadãos cientes dos fins dados as suas vidas, os libertando da alienação: "arrojados cometimentos que assinalam a marcha da civilização em um país de liberdade e de ordem". A melhor forma de fomentar a liberdade era através da ilustração, da educação lato sensu, do magistério da história, fundamentais para a ampliação do raio de alcance da razão e para o dito aperfeiçoamento moral dos cidadãos republicanos. A que custo?

\section{Virtudes epistêmicas}

A diligência era fundamental para a prática cientifica, sobretudo, a historiográfica. Assim, argumentava-se que os prazeres do espírito não se mostravam rápidos e inconstantes como os do sentido. Eles ofereciam, por outro turno, novos e intensos atrativos para o saber diligente do historiador. Qual a importância dessa virtude epistêmica?3 Ela favorecia o estudo da ciência da História junto ao estabelecimento metódico e meticuloso da verdade, combatendo erros e incertezas. Essa virtude tornava possivel, ainda, a exposição da verdade enquanto "lição dos tempos" (CASTRO, 1901, p. 320) para as gerações que se sucediam, movimentando, assim, o tempo histórico. A História, "depurada no cadinho da verdade" (CASTRO, 1901, p. 320), devia ser "santa como um pensamento do céu" (CASTRO, 1901, p. 320). Era, ainda, a concepção de verdade historicista que estava em jogo nas prescrições de Olegário Herculano de Aquino e Castro.

A diligência subsidiava a razão e a verdade no processo de análise e de exposição dos fatos. Ela movimentava o regime historiográfico metódico em busca dos erros informacionais acerca do passado, as lacunas da História, e das dúvidas que só produziam equivocos. A diligência buscava a excelência. Ela era condição para que o historiador firmasse um pacto de verdade com os seus leitores. Uma "missão nobre e dificil" (CASTRO, 1896, p. 356), pois a História só se fazia autorizada através destas outras virtudes epistêmicas: a objetividade, a justiça e a imparcialidade. Aqui está

3 A categoria "virtudes epistêmicas" foi elaborada por Herman Paul. Cf. PAUL, 2014. 
mais um exemplo das relações entre antigos e modernos em Olegário Herculano, visto que essas virtudes eram heranças antigas vertidas para os contextos historiográficos contemporâneos.

A insistência acerca do propósito de oferecer relatos verídicos remonta ao nascimento do gênero historiográfico entre os antigos, sobretudo, na crítica à tradição mítica e a ênfase na exclusão do fabuloso, enunciadas por Tucidides na célebre introdução a sua História da Guerra do Peloponeso (OLIVEIRA, 2013, p. 220).

O historiador devia ser, também, filósofo, podendo penetrar com acerto "nos recônditos mistérios dos fatos e suas causas latentes. Deve ser justo para dar a cada um o que the é devido, sem supor que a imparcialidade consiste em declamar contra todos" (CASTRO, 1896, p. 356). O historiador ideal do presidente do IHGB tinha como horizonte epistêmico a verdade, amparado pelas quatro principais virtudes assinaladas acima. Esse plano virtuoso orientava a performance da prática do historiador em seu processo de atribuição de sentidos ao processo histórico. Ele podia ser percebido, por exemplo, nas atividades do IHGB na República, especialmente no período em que Olegário Herculano foi o seu presidente.

A maneira como a História era narrada ilustrava bem o impacto dessas virtudes epistêmicas na prática do historiador. Era preciso que ela se distanciasse, argumenta o conferencista, das suas formas romanceadas, em que "historiadores-poetas" (CASTRO, 1896, p 356 se deixavam levar pelos "devaneios da imaginação" (CASTRO, 1896, p 356 e da "fantasia" (CASTRO, 1896, p 356. Mas também o oposto não era desejado: "o abuso da força" (CASTRO, 1896, p 356, "a violência de traços" (CASTRO, 1896, p 356. O tipo de escrita da História ideal era o de Hippolyte Taine: "a respeito de quem já se disse que ao folhear as páginas dos seus veementes escritos parecia ouvir-se o frêmito sonoro de finas lâminas de aço que entrechocam-se e cujo reflexo deslumbra" (CASTRO, 1896, p 356). Cientes da memória disciplinar que Olegário Herculano criou sobre esses gêneros de História, o que se via, ali, era mais um capítulo, que tinha as suas origens na antiguidade clássica, da guerra travada pela historiografia contra a ficção. Foi por meio dessa disposição que o gênero historiográfico se afastou dos demais discursos, forjando-se precisamente a partir da diferença que o credenciava "como savante, ou seja, como discurso portador de conhecimento" (OLIVEIRA, 2013, p. 222). Isso estava correto para o conselheiro, somando o desejo pela maleabilidade das formas de exposição do relato histórico.

\section{A disposição operatória da História}

A escrita da História possuía, para o presidente do IHGB, profundida social, estando em uma direção contrária à História acontecimental. Em suma, "não é a história uma simples ciência de datas [...]". A prática historiográfica também não era tão somente operada a partir da descrição, "que se limita à narração dos acontecimentos, sem pretender moralizá-los ou julgá-los" (CASTRO, 1892, p. 427). Ademais, a História devia se esquivar das teses fatalistas, as quais fixavam a ideia que os indivíduos possuíam pouco, ou nenhum, controle sobre as suas vidas. A operacionalização da História respeitava, assim, os preceitos modernos:

[...] é o estudo sério, profundo e refletido, a análise discreta e esclarecida, a crítica severa e judiciosa desses mesmos fatos, com exata e fundamental apreciação de suas causas, seus efeitos, sua intima relação com o passado, direta ligação com o presente e imediata influência sobre o futuro (CASTRO, 1892, p. 427).

A História, nesse sentido, atravessava as modulações do regime historiográfico metódico, se armava hermeneuticamente (moralmente) para que pudesse acompanhar pela pragmática-narrativa o curso do tempo, podendo, então, avaliar a conjuntura e aumentar a previsibilidade do futuro. No contexto em que essas reflexões eram enunciadas o IHGB vivia incertezas institucionais (GUIMARÃES, 2006), porém o desejo de Olegário Herculano, assim como o dos sócios fundadores do Instituto, de Francisco Adolfo de Varnhagen e de Capistrano de Abreu, por exemplo, "sinaliza um momento decisivo da própria disciplina história", que desde o Oitocentos concorria com a "metodização dos procedimentos com os quais se pretendia investigar o passado" (OLIVEIRA, 2013, p. 24). 
A operacionalização do saber histórico respeitava o "desenvolvimento harmônico das ideias e dos fatos da ordem intelectual e da ordem real" (CASTRO, 1892, p. 428) visando o enfrentamento da complexidade, concorrendo, para tanto, a Filosofia, o Direito, a Política, a Pdministração, as Ciências e as Artes; a atividade humana, enfim. Tudo isso atualizado em forma de cascata desde Homero, Tucidides, Xenofonte, Tito Livio, David Hume, Johann G. Herder, Thomas, Macaulay, Augustin Thierry, Jules Michelet, Adolphe Thiers, Alexandre Herculano e Cesare Cantù. Essa era, pois, a disposição epistemológica moderna da História em Olegário Herculano.

Em vista disso, os historiadores deveriam elaborar, também, um registro que oferecesse inteligibilidade ao processo que transformava fontes históricas em fatos históricos no âmbito da "História do tempo presente". Essa disposição era perpassada pela "retórica do historiador futuro" (DETONI, 2013), isto é, a História de uma época não podia ser escrita pelos seus contemporâneos (HRUBY, 2007). Esse esvaziamento da História do presente foi ditado para Olegário Herculano pelo ilustrado historiador inglês Edward Gibbon. A concepção de História do presidente do Instituto Histórico na passagem para o século XX era aceita como programa investigativo por parte considerável dos sócios. Esse programa sendo enunciado pelo presidente tornava oficial a legenda, porém, isso não significava que na agremiação carioca houvesse apenas essa concepção de História e de Historiografia. De todo modo, segundo o conselheiro os "obreiros de Clio" reuniriam com cuidado e disporiam com habilidade e diligência os "preciosos materiais" para que, assim, a História se refugiasse ante as "incertezas dos sofistas" e as "diversões dos declamadores" (CASTRO, 1892, p. 429). Desse modo, "não pertence aos contemporâneos pronunciar julgamento definitivo da história, diz Duvergier de Hauranne; mas, sim, o encargo de preparar os elementos necessários para que possa ser ele seguro e esclarecido" (CASTRO, 1892, p. 429). O presidente dizia que os sócios estavam muito próximos dos homens e dos fatos para a realização de apreciações históricas imparciais. "Cegam-nos os prodigios com o seu fulgor, e a voz imperiosa das paixões não consente que escutemos por enquanto a grande voz da história" (CASTRO, 1892, p. 429).

Olegário Herculano também se preocupava com a realização de uma nova História geral do Brasil, que pudesse atualizar aquela escrita em 1854 por Francisco Adolfo de Varnhagen, o Visconde de Porto Seguro. Essa História completa e integral, assegurava o Conselheiro, ainda não estava feita. O conferencista avaliava que muito se escrevia sobre o Brasil, mas uma "obra que satisfaça todas as condições exigidas para a perfeita história de um país, como é o nosso, grande em extensão e ainda maior em suas antigas e gloriosas tradições, se está sendo elaborada, só mais tarde será publicada" (CASTRO, 1896, p. 348).

Mas não cabia ao IHGB, em sua percepção, a realização desse desejo historiográfico, mas concorrer com o preparo e a coordenação dos elementos considerados seguros e indispensáveis para que no tempo certo se promovesse essa realização. Na concepção de Olegário Herculano, havia os obreiros, que também podiam ser chamados de "metódicos" ou de "heuristicos", e os historiadores arquitetos. Aos primeiros, que movimentavam o regime historiográfico metódico, incumbia o trabalho de contribuir com a operação dos futuros historiadores. Essa prescrição de Olegário era sugerida para os esforços investigativos do IHGB na passagem para o século XX. Esses atores intelectuais deveriam colher, criticar e entender o significado de documentos, de memórias, de informações, de cartas e de mapas esparsos não aproveitados; corrigindo, retificando e complementando os estudos sobre a História nacional. Esse posicionamento não encerrava as atividades do IHGB, marcado pela pluralidade de vozes.

Não era o momento para a síntese segundo o presidente do IHGB, devendo aqueles que se ocupavam com a História prosseguirem na organização e no preparo dos materiais considerados pertinentes para a sua futura realização. Esse movimento tornava-se necessário porque na exposição dos fatos, na apreciação dos caracteres formativos da nação, na análise das instituições e dos 
costumes verificavam-se incorreções e lacunas, "que só o amadurecido estudo e judiciosa critica poderão ainda preencher" (CASTRO, 1899, p. 411).

Para Olegário Herculano, a História era um "espelho" que refletia fielmente a ação dos sujeitos e as situações históricas. De modo que a reprodução dessas duas dimensões inscritas no passado "de tão variadas formas representa a realidade, a rigorosa e nua verdade em quadro vivos e animados" (CASTRO, 1899, p. 411). Mas para o conselheiro ainda era pouco. E o nosso autor se valia de um raciocínio de Newton para corroborar o ensejo: "apanhamos apenas algumas finas conchas na praia que percorremos, vendo diante de nós inexplorado estender-se o intérmino oceano da verdade" (CASTRO, 1890, 537). Assim, para se escrever a História do Brasil não era o bastante a vida de um sujeito cognoscente, a atividade de uma instituição ou a boa vontade de toda uma geração. "A história do Brasil é uma obra vasta e profunda, que demanda muito estudo, muita reflexão e diligência, além de largo tempo e recursos materiais que ainda nos faltam (CASTRO, 1902, p. 340).

\section{A História como literatura}

Olegário Herculano inscrevia a História nos horizontes do conceito moderno de Literatura, da forma como percebido, por exemplo, pelos românticos João Manuel Pereira da Silva e Domingos José Gonçalves de Magalhães e, anos depois, pelo cientificista Sílvio Romero. Assim a História era adjetivada: "Gênero de literatura tão elevado, tão útil e proveitoso, quão praticamente conforme ao espírito e a vocação dos nossos tempos, primeiro canto do alvorecer da vida nacional, na frase elegante de um escritor, e último trabalho literário de um povo [...]. (CASTRO, 1892, p. 427). Os estudos históricos desenvolvidos no IHGB, supostamente em "conformidade com o fim de sua criação", compunham o acervo do domínio da literatura nacional, em tese, pouco explorado pelos homens de letras do Brasil (CASTRO, 1896, p. 349).

Após refletir sobre as relações entre as literaturas brasileira e portuguesa, o que as aproximava e o que as distanciava, Olegário Herculano indagava-se: o que é a literatura de um país civilizado, visto que somente da civilização ela procede? Seguindo Friedrich Schlegel, o conselheiro percebia a literatura como um conjunto de símbolos que representavam o "espírito" de uma época ou mesmo o caráter e a fisionomia da nação. Vou fazer mais uma citação porque esta passagem é importante para que se compreenda o lugar da História nos horizontes da literatura da forma como estabelecido pelo presidente do IHGB:

\begin{abstract}
É o conhecimento de tudo o que diz respeito à doutrina científica ou literária e às obras que fazem dela aplicação; é a suma das produções da inteligência, representando as ideias e os sentimentos de uma época, e exprimindo com fidelidade o grau de desenvolvimento moral e intelectual a que tem atingindo a sociedade. [dado que] ela é a própria imagem da sociedade (CASTRO, 1896, p. 350).
\end{abstract}

É possivel comparar com o romântico Pereira da Silva:

[...] a literatura é hoje a reunião de tudo o que a
imaginação exprime pela linguagem, abraçan-
do todo o império, em que exerce a inteligência
humana seu poderio; é o resumo dos hábitos
e grandeza dos povos, e a história progressiva
e circunstanciada do espirito humano com as
suas superstições, crenças, e carácter próprio;
é a apreciação da influência dos elementos
uns sobre os outros no espirito das diferentes
épocas, é a Filosofia, a História, a Eloquência
e a Poesia (SILVA, 1836, p. 217).

Agora é visto o papel da Literatura na formação da nação segundo Gonçalves de Magalhães. A passagem é por demais conhecida, mas extremante proveitosa para se acompanhar os significados das prescrições historiográficas de Olegário Herculano:

\begin{abstract}
A literatura de um povo é o desenvolvimento do que ele tem de mais sublime nas ideias, de mais filosófico no pensamento, de mais heroico na moral, e de mais belo na natureza; é o quadro animado de suas virtudes e de suas paixões, o despertador de sua glória, e o reflexo progressivo de sua inteligência; e quando esse povo, ou essa geração, desaparece da superfície da terra com todas as suas instituições, crenças e costumes, escapa a literatura aos rigores do tempo para anunciar qual fôra o carácter e a importância do povo, do qual é Ela o único representante na posteridade (MAGALHÂES, 1836, p. 132).
\end{abstract}

O conceito de Literatura em Sílvio Romero trazia consigo a mesmo aspecto total da geração 
romântica. A literatura para o polemista sergipano "tem a amplitude que lhes dão os escritores alemães. Compreende todas as manifestações da inteligência de um povo: - a política, economia, arte, criações populares, ciências[...]" (ROMERO, 1902, p. 102) e não "[...] somente as intituladas belas-letras, que cifrava-se quase exclusivamente na poesia" (ROMERO, 1902, p. 102)! Parecia que o projeto intelectual dos românticos impactava a obra do intelectual nordestino, pelo menos no que tange a essa compreensão alargada do conceito de Literatura. Portanto, também em Romero a História da Literatura apresentava-se como um espaço privilegiado para a interpretação do Brasil. Através dela era possivel encontrar a sintese do movimento que resultava na formação brasileira. Talvez a diferença entre Romero e os românicos estivesse, pois, impressa no suposto caráter científico da História Literária do primeiro.

No limite, esses autores, inclusive Olegário Herculano, dotavam a Literatura de espessura histórica, podendo, então, compreender a experiência brasileira. Essa disposição da Literatura unificava passado, presente e futuro a partir de uma ideia de nação entendida enquanto a manifestação progressiva de uma entidade histórica. A História era concebida, a partir desse conceito de Literatura, como Literatura histórica, da forma como queria o presidente do IHGB.

A Literatura, que era considerada "vasta como o pensamento" (CASTRO, 1896, p. 350) e "profunda como a razão" (CASTRO, 1896, p. p. 350), apresentava-se, pois, como a grande sintese intelectual disponivel, revelando-se através de múltiplas formas e tendências: História, Filosofia, Moral, Religião, Política, Administração, Eloquência, Poesia, Teatro, Belas Artes. A História enquanto uma manifestação de entendimento da Literatura tornava possivel a expansão do "espírito ilustrado", que por intermédio da abordagem sobre o passado adquiria as lições consideradas proveitosas para a educação das novas gerações, sendo possivel guiá-las junto à investigação da verdade. A literatura histórica de Olegário Herculano era capaz de perceber o caleidoscópio da vida social de modo realístico, ou verdadeiro.
A Literatura se transmutava em várias direções, abrangendo todas as manifestações do entendimento humano. Mas as suas ideias eram condicionadas pelo tempo, pelos lugares, pelas instituições, pelos costumes e pelas tradições do povo o qual representava. Nomes de peso compunham o cânone de Olegário Herculano: Heródoto, Tito Lívio, Homero, Virgílio, Tasso, Milton ou Corneille. O merecimento das obras desses escritores residia no fato de assinalar, pela "História ou pela poesia" (CASTRO, 1896, p. 350), a especificidade de uma época e simbolizar uma nação.

Deixo Olegário Herculano conceituar literatura: "[...] a literatura é a expressão da indole, do caráter, da educação moral e intelectual de um povo ou de uma época; determina o grau de sua civilização; significa engrandecimento, ilustração e progresso" (CASTRO, 1896, p. 351). Como visto, havia uma longa tradição nacional que concebia a literatura nesses moldes. Dito de outro como: como espelho da nação (VELLOSO, 1988). Tendo isso em vista, o onselheiro colocava a questão: por qual razão não havia literatura nacional, quando,

\begin{abstract}
prodigamente favorecidos pela natureza, esclarecidos pelo estudo e guiados pela observação e pela experiência tantas provas temos dado de que nos achamos habilitados a tomar parte, posto que modesta, sempre digna, no festivo convívio das ciências e das letras (CASTRO, 1896, p. 351)?
\end{abstract}

A resposta era que o Brasil possuía, sim, uma literatura independente, sendo que o único problema em termos identitários era o compartilhamento da língua com os portugueses. Porém, não eram as linguas que caracterizavam uma Literatura. Ter uma Literatura própria era sinal de civilização. Recuperando Gonçalves de Magalhães: cada povo possuía a sua própria Literatura, cada sujeito histórico o seu caráter particular, cada árvore o seu fruto. A Literatura nacional não podia ser o reflexo da civilização de outro povo. Assim, mais uma vez Olegário Herculano conceituava literatura: aquilo que caracterizava a "literatura é a inspiração criadora, é o espirito que a domina, a ideia que representa; é a feição, a fisionomia que retrata ao natural [...]" (CASTRO, 1896, p. 352) "as tendências e as paixões do es- 
critor. Esse princípio literário e artístico resulta da influência dos sentimentos, das crenças, dos costumes e hábitos sociais (...)" (CASTRO, 1896, p. 352). Essa disposição não impedia, de qualquer forma, a imparcialidade da Literatura histórica. Essas paixões nada tinham de partidárias.

Então era chegado o momento decisivo da reflexão de Olegário Herculano, qual seja, aquele que circunscrevia melhor a noção de Literatura histórica. Eram poucas as obras dessa natureza no Brasil, porém, nesses trabalhos destacavam-se as preocupações dos historiadores com a "investigação da verdade". Uma parcela considerável desses sujeitos buscava a fiel exposição dos fatos e a sua rigorosa análise, abordando passado, presente e futuro em uma disposição progressiva. O cânone historiográfico nacional, do século XVI ao XIX, de Gândavo a Américo Brasiliense, disponibilizava apreciações justas sobre "homens e coisas" (CASTRO, 1896, p. 353) que no plano da temporalidade impactavam a "marcha da vida social" (CASTRO, 1896, p. 353), porém, em um grau de complexidade evolutivo, cujo cume era o moderno conceito de literatura.

Ao conceber a História como Literatura, nos moldes explicitados acima, Olegário Herculano podia conceber um caleidoscópio analítico capacitado no enfrentamento da complexidade da realidade histórica. Por ser espelho da nação, a Literatura histórica traduzia o espírito de cada idade fielmente. No caso da Literatura histórica do conselheiro essa disposição era realizada com a diligência do regime historiográfico metódico. Por possuir um forte pendor social essa Literatura estava apta a ilustrar a nação nos caminhos da civilização. Estávamos diante de uma História total? Pereira da Silva, terminando, colocava nos seus devidos termos o tipo de literatura desejada por Olegário Herculano e o seu papel ilustrado: "a literatura é sempre a expressão da civilização: ambas caminham em paralelo: a civilização consistindo no desenvolvimento da sociedade e do individuo (SILVA, 1836, p. 214).

\section{Referências}

ARAUJO, Valdei Lopes de. Sobre a permanência da expressão historia magistra vitae no século XIX brasileiro. In: NICOLAZZI, Fernando; MOLLO, Helena Miranda; ARAUJO, Valdei Lopes de (orgs.). Aprender com a história? O passado e o futuro de uma questão. Rio de Janeiro: Editora da FGV, 2011

CASTRO, Olegário Herculano de Aquino. Alocução do presidente do Instituto Histórico e Geográfico Brasileiro. RIHGB, tomo LV, parte II, 1892.

CASTRO, Olegário Herculano de Aquino. Alocução do presidente do Instituto Histórico e Geográfico Brasileiro. RIHGB, tomo LIX, parte II, 1896.

CASTRO, Olegário Herculano de Aquino. "Alocução do presidente do Instituto Histórico e Geográfico Brasileiro". RIHGB, tomo LXI, parte II, 1898.

CASTRO, Olegário Herculano de Aquino. "Alocução do presidente do Instituto Histórico e Geográfico Brasileiro". RIHGB, tomo LXII, parte II, 1899.

CASTRO, Olegário Herculano de Aquino. "Alocução do presidente do Instituto Histórico e Geográfico Brasileiro". RIHGB, tomo LXIII, parte II, 1900.

CASTRO, Olegário Herculano de Aquino. "Alocução do presidente do Instituto Histórico e Geográfico Brasileiro". RIHGB, tomo LXIV, parte II, 1901.

CASTRO, Olegário Herculano de Aquino. "Alocução do presidente do Instituto Histórico e Geográfico Brasileiro". RIHGB, tomo LXV, parte II, 1902.

CASTRO, Olegário Herculano de Aquino. "Alocução do presidente do Instituto Histórico e Geográfico Brasileiro". RIHGB, tomo LXVIII, parte II, 1905.

DETONI, Piero di Cristo Carvalho. A sintese como desafio historiográfico na Primeira República. Pequenos estudos de caso. Dissertação (Mestrado em História) - Programa de Pós-graduação em História, Universidade Federal de Ouro Preto, Mariana 2013. http://www.repositorio. ufop.br/handle/123456789/6124

DUFAL, Blaise. Le fantasme de la perfection originelle: La Grèce Antique comme matrice du modèle civilisationnel. Cahiers Mondes anciens, v. 9, n. 11, 2018. https:// doi.org/10.4000/mondesanciens.2075

ELIAS, Norbert. O processo civilizador. Vol. 1: Uma história dos costumes. Rio de Janeiro: Zahar, 2011.

GOMES, Angela de Castro. A república, a história e o IHGB. Belo Horizonte: Argumentum, 2009.

GUIMARÃES, Lucia Maria Paschoal. Da Escola Palatina ao Silogeu: Instituto Histórico e Geográfico Brasileiro. Rio de Janeiro: Museu da República, 2006.

GUIMARÃES, Manoel Luiz Salgado. Nação e civilização nos trópicos: o Instituto Histórico e Geográfico Brasileiro e o projeto de uma história nacional. Estudos Históricos, Rio de Janeiro, n.1, 1988. 
GUMBRECHT, Hans Ulrich. Depois de "Depois de aprender com a história", o que fazer com o passado agora? In: NICOLAZZI, Fernando; MOLLO, Helena Miranda; ARAUJO, Valdei Lopes de (orgs.). Aprender com a história? O passado e o futuro de uma questão. Rio de Janeiro: Editora da FGV, 2011.

HARTOG, François. Crer em história. Belo Horizonte: Autêntica, 2017.

HEGEL, Georg Wilhelm Friedrich. Os três métodos de escrever a história. In: Razão na história. Uma introdução geral à filosofia da história. São Paulo: Editora Moraes Ltda, 1990.

HRUBY, Hugo. Obreiros diligentes e zelosos auxiliando no preparo da grande obra: a história do Brasil no Instituto Histórico e Geográfico Brasileiro (1889-1912). Dissertação (Mestrado em História) - Programa de Pós-graduação em história, Pontifícia Universidade Católica do Rio Grande do Sul - PUCRS, Porto Alegre, 2007. http://tede2.pucrs.br/tede2/handle/tede/2500

KOSELLECK, Reinhart. Historia Magistra Vitae. Sobre a dissolução do topos na história moderna em movimento". In: KOSELLECK, Reinhart. Futuro passado. Contribuição a semântica dos tempos históricos. Rio de Janeiro: Contraponto, 2006.

MAGALHÃES, Domingos José Gonçalves de. Ensaio sobre a história da literatura do Brasil. Nitheroy, revista brasiliense. Ciências, letras e artes, n⿳ $\|, 1836$, (Edição fac-similar organizada por Plínio Doyle. São Paulo: Brasiliense, 1978.

NETO, Mauro Franco. Ciência, evolução e experiência do tempo no fin de siècle: estudos e revisões sobre letrados brasileiros e argentinos. Dissertação (Mestrado em História Social da Cultura) - Programa de Pós-graduação em História Social da Cultura, Pontifícia Universidade Católica do Rio de Janeiro, Rio de Janeiro, 2015.

OLIVEIRA, Maria da Glória de. A crítica ao fabuloso e a verdade histórica nos estudos de Francisco Adolfo de Varnhagen e Joaquim Manoel de Macedo. In: SILVA, Ana Rosa Cloclet da; NICOLAZZI, Fernando; PEREIRA, Mateus (orgs.). Contribuições à história da historiografia brasileira. São Paulo: HUCITEC/FAPEMIG, 2013.

OLIVEIRA, Maria da Glória de. Crítica, método e escrita da história em João Capistrano de Abreu. Rio de Janeiro: FGV, 2013.

PAUL, Herman. What is a Scholarly Persona? Ten theses on virtues, skills, and desires. History \& Theory, v. 53, n. 3, 2014. https://doi.org/10.1111/hith.10717

PEREIRA, Mateus H. F.; SANTOS, Pedro Afonso C.; NICODEMO, Thiago Lima. Uma introdução à história da historiografia brasileira (1870-1970). Rio de Janeiro: Editora da FGV, 2018.

ROMERO, Sílvio. História da literatura brasileira. Rio de Janeiro: H. Garnier, Livreiro-editor, 1902.

SILVA, João Manoel Pereira da. Estudos sobre a literatura. Nitheroy, revista brasiliense. Ciências, letras e artes, $n^{\circ}$ II, 1836, (Edição fac-similar organizada por Plínio Doyle. São Paulo: Brasiliense, 1978).

\section{Piero Detoni}

Doutorando em História pela Universidade de São Paulo (USP), São Paulo, SP, Brasil.

\section{Endereço para correspondência}

Piero Detoni

Universidade de São Paulo

R. da Reitoria, 374, Cidade Universitária

Butantã, 05508220

São Paulo, SP, Brasil 